\title{
Microbially mediated barite dissolution in anoxic brines
}

\author{
Authors: Bingjie Ouyang ${ }^{1}$, Denise M. Akob ${ }^{2}$, Darren Dunlap ${ }^{2,3}$, and Devon Renock ${ }^{1^{*}}$,
}

${ }^{1}$ Department of Earth Sciences

Dartmouth College,

Hanover, New Hampshire 03755, USA

${ }^{2}$ US Geological Survey, National Research Program, Reston, Virginia 20192 USA

${ }^{3}$ Present address: Boeing Research \& Technologies, The Boeing Company, Huntsville, AL 35824 USA

*corresponding author: Devon Renock

Phone: +.1. 603.646.3101

Fax: +.1. 603-646-3922

email: Devon.J.Renock@Dartmouth.edu

This draft manuscript is distributed solely for purposes of scientific peer review. Its content is deliberative and predecisional, so it must not be disclosed or released by reviewers. Because the manuscript has not yet been approved for publication by the U.S. Geological Survey (USGS), it does not represent any official USGS finding or policy. 
Ouyang et al.

\section{ABSTRACT:}

Fluids injected into shale formations during hydraulic fracturing of black shale return with extraordinarily high total-dissolved-solids (TDS) and high concentrations of barium (Ba) and radium (Ra). Barite, $\mathrm{BaSO}_{4}$, has been implicated as a possible source of $\mathrm{Ba}$ as well as a problematic mineral scale that forms on internal well surfaces, often in close association with radiobarite, $(\mathrm{Ba}, \mathrm{Ra}) \mathrm{SO}_{4}$. The dissolution of barite by abiotic processes is well quantified. However, the identification of microbial communities in flowback and produced water necessitates the need to understand barite dissolution in the presence of bacteria. Therefore, we evaluated the rates and mechanisms of abiotic and microbially-mediated barite dissolution under anoxic and hypersaline conditions in the laboratory. Barite dissolution experiments were conducted with bacterial enrichment cultures established from produced water from Marcellus Shale wells located in northcentral Pennsylvania. These cultures were dominated by anaerobic halophilic bacteria from the genus Halanaerobium. Dissolved $\mathrm{Ba}$ was determined by ICP-OES and barite surfaces were investigated by SEM and AFM. Our results reveal that: 1) higher amounts of barium (up to $\sim 5 \times$ ) are released from barite in the presence of Halanaerobium cultures compared to brine controls after 30 days of reaction, 2) etch pits that develop on the barite (001) surface in the presence of Halanaerobium exhibit a morphology that is distinct from those that form during control experiments without bacteria, 3) etch pits that develop in the presence of Halanaerobium exhibit a morphology that is similar to the morphology of etch pits formed in the presence of strong organic chelators, EDTA and DTPA, and 4) experiments using dialysis membranes to separate barite from bacteria suggest that direct contact between the two is not required in order to promote dissolution. These results suggest that Halanaerobium increase the rate of barite dissolution in anoxic and high ionic strength solutions. Additionally, the 
Ouyang et al.

increase in rate occurs without direct microbe-mineral contact suggesting that metabolites secreted by the bacteria may be responsible for promotion of dissolution. The findings of this study have implications for understanding barium cycling in marine/hypersaline environments, release of barium (and associated radium) from waste solids generated from energy and mining industries, as well as potential for developing new anti-scaling chemicals.

\section{INTRODUCTION}

The growth and dissolution of mineral barite, $\mathrm{BaSO}_{4}$, has been the focus of numerous studies in recent years due to: 1) barite being a common and problematic scale-forming mineral and solid-phase host for radium in the water, oil, and gas industry (Hamlat et al., 2003; Sorbie and Mackay, 2000; Zhang et al., 2015), and 2) the potential to utilize barite as a tracer of marine paleoproductivity and paleocirculation (Dehairs et al., 1980; Dymond et al., 1992; Griffith and Paytan, 2012). Most of what is known about barite growth/dissolution derives from fundamental studies of abiotic processes (Becker et al., 2005; Bosbach et al., 1998; Kowacz and Putnis, 2008; Pina et al., 1998a; Putnis et al., 1995b; Risthaus et al., 2001; Wang et al., 1999, 2000). The few studies of microbially-mediated dissolution have shown that sulfate-reducing bacteria (SRB), primarily from the genus Desulfovibrio and Desulfobacterium, can promote dissolution under sulfate-limiting conditions, though the specific mechanism(s) responsible is unclear (Baldi et al., 1996; Bolze et al., 1974; Karnachuk et al., 2002; Phillips et al., 2001). Furthermore, all of these microbially-mediated dissolution studies were performed under freshwater conditions where barite is highly insoluble $\left(\log \mathrm{K}_{\mathrm{sp}}=9.96\right.$ at $20{ }^{\circ} \mathrm{C}($ Blount, 1977)).

An area that has received little attention thus far is the effect of halophilic organisms on barite growth/dissolution processes occurring under anoxic saline-hypersaline conditions; of particular relevance are conditions occurring in the subsurface of unconventional oil and gas 
Ouyang et al.

wells during hydraulic fracturing. In these systems, high salinity brines interact with barite mineral scale on the internal surfaces of the well and also with natural barite that is present in the targeted rock formations. Recent studies demonstrate that halophilic organisms are not just present in these hypersaline environments, but are likely thriving despite industry reports of the addition of biocides to injected fluids (Cluff et al., 2014; Fichter et al., 2008; Kahrilas et al., 2015; Struchtemeyer et al., 2012). To date, there have been no studies evaluating the role that halophilic organisms might play in barite mineral dissolution.

Our study focuses on halophilic organisms harvested from water co-produced with extraction of oil and gas from Marcellus Shale wells where flowback or produced water (herein designated PW) can reach salinities that are 10x greater than seawater with total dissolved solid (TDS) content often exceeding 200,000 mg/L (or ppm) (Akob et al., 2015; Chapman et al., 2012; Rowan et al., 2015). The source of the TDS is a combination of the products of water-rock interactions and the mixing of surface water with natural brines present in the formation (Capo et al., 2014; Haluszczak et al., 2013; Renock et al., 2016; Stewart et al., 2015). While the major dissolved ions are sodium, calcium and chloride, produced water contains appreciable amounts of other dissolved ions including magnesium, strontium, barium, and naturally occurring radioactive material or NORM, predominantly Ra-226 (Rowan et al., 2011; Rowan et al., 2015). Barium is shown to be predominantly sourced from phyllosilicate clays in the Marcellus Shale (Renock et al., 2016), but authigenic barite present in barium-rich intervals within the rock is also a possible source (Lash, 2014; Niu et al., 2016). A study by Renock et al. (2016) revealed that 5 to $25 \%$ of the total $\mathrm{Ba}$ in the Marcellus Shale can be leached from the shale under the anoxic and high ionic strength conditions typical of produced waters over a contact time of just 7 days. 
Ouyang et al.

We hypothesized that microbes could be mediating dissolution in light of the aforementioned microbially-mediated dissolution studies and studies showing the presence of HS-producing, fermenting, and methanogenic bacteria in PW from Marcellus Shale wells in Pennsylvania (Akob et al., 2015; Cluff et al., 2014; Fichter et al., 2008; Mohan et al., 2013; Struchtemeyer and Elshahed, 2012). The latter studies have shown that $>90 \%$ of the community in high TDS PW is composed of halophilic bacteria (i.e., Halanaerobium and Halolactibacillus) (Akob et al., 2015; Cluff et al., 2014) and organisms are viable in PW (Akob et al., 2015).

Acknowledging the inherent challenges in assessing the role of microorganisms in barite dissolution occurring under real hydraulic fracturing conditions, here we report the results of a study to quantify the extent to which halophilic bacteria affect barite dissolution rates and mechanisms under laboratory controlled conditions designed to simulate PW conditions. Results from abiotic and bacterial incubation experiments can be used to predict the effect of microbes on barite dissolution during hydraulic fracturing as well as in other natural saline-hypersaline environments.

\section{METHODS}

\subsection{Experimental design}

A series of batch experiments were set up to investigate abiotic and biotic dissolution of pure barite in hypersaline (brine) or freshwater solutions (see Table 1). Biologically mediated dissolution was tested using 3 halophilic bacterial enrichment cultures from Marcellus Shale PW (Akob et al., 2015) and the freshwater SRB, Desulfovibrio vulgaris (described below). Abiotic control experiments were run in parallel using sterile brine and freshwater media (described below) without bacteria added. Experiments were carried out to evaluate dissolution with direct bacterial contact (designated Experiment 1) and without direct contact (designated Experiment 2) 
Ouyang et al.

(see Table 1). Crystals of $99 \%$ pure, tabular barite (Pulsifer Mine, ME) were used in batch experiments. Compositional purity and mineral structure were confirmed using X-ray fluorescence (XRF) and X-ray diffraction analysis (XRD), respectively (data not shown). The crystals were cleaved and cut to expose fresh (001) surfaces with dimensions of $\sim 9-12 \mathrm{~mm}^{2}$ and inspected with SEM-EDS to ensure each surface was uniform. Each crystal was then encapsulated with zero sulfur resin (EMbed $812 \mathrm{kit}$ ), so that only the (001) face was exposed to the solution and affixed to round glass cover slides.

In Experiment 1, a single prepared barite crystal $(\sim 0.05 \mathrm{~g})$ was placed with the $(001)$ surface face-up in the bottom of a $100 \mathrm{~mL}$ serum bottle without liquid added. Bottles were then flushed with $80 \% \mathrm{~N}_{2} / 20 \% \mathrm{CO}_{2}$ to create an anoxic headspace, then sealed with butyl rubber stoppers and aluminum crimp seals, prior to autoclaving at $121^{\circ} \mathrm{C}$ for $30 \mathrm{~min}$. Crystals were examined before and after autoclaving with SEM and no etching of the barite surface was observed due to the autoclaving process. After autoclaving, $30 \mathrm{~mL}$ of sterile, anoxic brine medium was added using an anoxic, aseptic technique. Biotic bottles were inoculated with $1 \mathrm{~mL}$ of the appropriate bacterial culture then all bottles were incubated statically at $37^{\circ} \mathrm{C}$ in the dark.

For Experiment 2, prepared barite crystals were placed into Spectra/Por 7 tubing (Spectrum Laboratories, Inc., Rancho Dominguez, CA) and sealed using weighted dialysis bag clips (Spectrum Laboratories, Inc., Rancho Dominguez, CA). The Spectra/Por 7 dialysis membrane has a molecular weight cutoff (MWCO) of $50 \mathrm{kD}$ (equal to $\sim 4 \mathrm{~nm}$ pore diameter), which is large enough to contain microbial cells but allows movement of ions and metabolites. Dialysis tubing and clips were rinsed with distilled water $\left(\mathrm{DI} \mathrm{H}_{2} \mathrm{O}\right)$ and then autoclaved in DI $\mathrm{H}_{2} \mathrm{O}$. After autoclaving, the dialysis tubing was clipped on one end, filled with sterile media and a barite crystal was loaded into the dialysis tubing. The dialysis tube was clipped closed to create a bag, 
Ouyang et al.

which was then placed into a $125 \mathrm{ml}$ Schott (Schott North America, Inc., Elmsford, NY) bottle filled with $60 \mathrm{~mL}$ of sterile media. All materials were handled using aseptic technique. The bottle containing medium and dialysis bag was then bubbled with sterile $80 \% \mathrm{~N}_{2} / 20 \% \mathrm{CO}_{2}$ for 10 min, prior to sealing with $45 \mathrm{~mm}$ black butyl rubber stoppers and GL 45 aperture caps (Glasgerätebau Ochs, Bovenden / Lenglern, Germany). Biotic bottles were inoculated with $1 \mathrm{~mL}$ of the appropriate bacterial culture; then all bottles were incubated statically at $37^{\circ} \mathrm{C}$ in the dark.

\subsection{Bacterial Cultures and Media}

Three anaerobic, halophilic bacterial enrichment cultures and a single freshwater SRB isolated were used to compare microbially mediated barite dissolution under hypersaline versus freshwater conditions. The three enrichment cultures (CU823, MA284 and ST460) were obtained from Pennsylvania shale gas PW samples that contained high concentrations of dissolved barium ([Ba] > $3700 \mathrm{ppm})$, as described in Akob et al. (2015). Organisms within the order Halobacteroidaceae (including members of the Halanaerobium genus and unclassified members of the Halanaerobiaceae family dominate the cultures ( $>80 \%$ of total sequence reads) (Akob et al. 2015 and Fig. S1 in supplemental information), which are known anaerobic and halophilic fermentative bacteria. Halanaerobium-related organisms dominate microbial communities in waste brines from oil and gas production (Cluff et al., 2014; Davis et al., 2012; de Oliveira et al., 2008; Mohan et al., 2013; Ravot et al., 1997). Microbial community characterization of PW samples from wells CU823 and ST460-MS, the source of the CU823 enrichment culture and a lateral on the same well pad of ST460-Burket, the source of the ST460 culture, respectively, also showed that members of the order Halobacteroidaceae were dominant (>94\% total sequence reads; Fig. S1). In addition, these bacteria are often found in naturally high salinity environments including marine systems (Eder et al., 2001; Kaye and Baross, 2004; 
Ouyang et al.

Ollivier et al., 1994; Rengpipat et al., 1988) and hypersaline lakes (Abdeljabbar et al., 2013; Brown et al., 2011; Ollivier et al., 1994).

Cultures CU823, MA284 and ST460 were initially enriched in an artificial brine medium (ABM) described in Akob et al. (2015). However, for dissolution experiments the medium was modified to remove aqueous sources of $\mathrm{Ba}$. Modified ABM ( $\mathrm{pH} 6.5$ ), hereafter referred to as "brine" contained per liter: contained per liter: $66 \mathrm{~g} \mathrm{CaCl}_{2} \cdot 2 \mathrm{H}_{2} \mathrm{O}, 17 \mathrm{~g} \mathrm{MgCl}_{2} \cdot 6 \mathrm{H}_{2} \mathrm{O}, 6.5 \mathrm{~g}$ $\mathrm{SrCl}_{2} \cdot 6 \mathrm{H}_{2} \mathrm{O}, 125 \mathrm{~g} \mathrm{NaCl}, 1.5 \mathrm{~g} \mathrm{KCl}, 0.25 \mathrm{~g} \mathrm{NaHCO}_{3}, 1.25 \mathrm{~g} \mathrm{NaBr}$ (anhydrous), $0.08 \mathrm{~g}$ $\mathrm{MnCl}_{2} \cdot 4 \mathrm{H}_{2} \mathrm{O}, 1.7 \mathrm{~g} \mathrm{BaCl}_{2} \cdot 2 \mathrm{H}_{2} \mathrm{O}, 1 \mathrm{~g} \mathrm{NH} \mathrm{NH}_{4} \mathrm{Cl}$ and $0.2 \mathrm{~g} \mathrm{KH}_{2} \mathrm{PO}_{4}, 1 \mathrm{ml}$ vitamin solution 141 (Balch et al., 1979), $1 \mathrm{ml}$ trace element solution SL9 (Tschech and Pfennig, 1984), $1 \mathrm{~g} / \mathrm{L}$ yeast extract, $0.5 \mathrm{mM} \mathrm{FeCl}_{2}$, and $5 \mathrm{mM}$ sodium acetate under a headspace of $80 \% \mathrm{~N}_{2} / 20 \% \mathrm{CO}_{2}$ gas.

To compare differences in dissolution between halophilic and freshwater bacteria, we used a Desulfovibrio vulgaris strain 29579, obtained from the American Type Culture Collection (ATCC), a well-characterized SRB, in parallel incubations. D. vulgaris was cultured in a modified Widdel and Bak medium (Widdel and Bak, 1992), hereafter referred to as "freshwater" medium. The freshwater medium contained per liter: $1.0 \mathrm{~g} \mathrm{NaCl}, 0.4 \mathrm{~g}$ of $\mathrm{MgCl}_{2} * 6 \mathrm{H}_{2} \mathrm{O}, 0.1 \mathrm{~g}$ of $\mathrm{CaCl}_{2} * \mathrm{H}_{2} \mathrm{O}, 0.5 \mathrm{~g} \mathrm{KCl}, 0.3 \mathrm{~g}$ of $\mathrm{NH}_{4} \mathrm{Cl}, 0.6 \mathrm{~g}$ of $\mathrm{KH}_{2} \mathrm{PO}_{4}, 2.5 \mathrm{~g} \mathrm{NaHCO}, 0.5 \mathrm{mM} \mathrm{FeCl}, 1 \mathrm{ml}$ vitamin solution 141 (Balch et al., 1979), $1 \mathrm{ml}$ trace element solution SL9 (Tschech and Pfennig, 1984), $1 \mathrm{~g} / \mathrm{L}$ yeast extract, $0.5 \mathrm{mM} \mathrm{FeCl}_{2}$, and $5 \mathrm{mM}$ sodium acetate under a headspace of $80 \%$ $\mathrm{N}_{2} / 20 \% \mathrm{CO}_{2}$ gas.

\subsection{Sample analyses}

At each time point, crystals were removed from the brine or freshwater medium in a Coy anaerobic chamber (Coy Laboratories, Grass Lake, MI) and washed by dipping in sterile DI $\mathrm{H}_{2} \mathrm{O}$. An aliquot of liquid medium was sampled at each time point, filtered through a $0.2 \mu \mathrm{m}$ 
Ouyang et al.

membrane filter, diluted $50 \times$, and then acidified with $5 \% \mathrm{HNO}_{3}$. Any precipitates that were collected on the $0.2 \mu \mathrm{m}$ membrane filters were weighed and dissolved with concentrated $\mathrm{HCl}$ (37.2\%) for cation analysis. Barium concentrations were analyzed by an inductively coupled plasma optical emission spectrometer (ICP-OES, Thermo Iris Intrepid 2). Barite (001) surface morphologies were observed using a Hitachi tabletop TM3000 Scanning Electron Microscope (SEM). A Multimode 8 atomic force microscope (AFM) was used to quantify etch pit dimensions. The surfaces were monitored in real time by a Multimode 8 AFM system operating in peak force tapping mode in which the cantilever is oscillated well below resonance, this results in a continuous series of force-distance curves. A silicon nitride cantilever with reflective aluminum coating on the back side was used. The cantilever has a nominal length of 115 um, a nominal tip radius of $2 \mathrm{~nm}$, and a force constant of $0.4 \mathrm{~N} / \mathrm{m}$.

\section{Results}

\subsection{Barium in solution}

For batch Experiment 1, Figure 1 shows dissolved Ba concentrations over time during the 135-day incubation. Barium concentrations increase in all of the experiments in artificial brine (both control and inoculated treatments). For comparison, all freshwater experiments show relatively lower concentrations throughout $(<0.083 \mu \mathrm{g} / \mathrm{mL})$. Experiments with PW enrichment cultures show increased concentrations of Ba relative to that of the brine control and freshwater experiments for the first 80 days of the experiment. Specifically, the consortia from well CU823 consistently show higher Ba concentrations at each sampling time (i.e., 4-5x higher than the brine control at day 30). The increase in $\mathrm{Ba}$ concentration over time reflects an asymptotic approach to solution saturation with respect to barite under these ionic strengths (barite solubility at $2 \mathrm{M} \mathrm{NaCl}=17 \mu \mathrm{g} / \mathrm{mL}$ (Templeton, 1960)). Throughout the experiment, $\mathrm{pH}$ values were $6.5 \pm$ 
Ouyang et al.

0.5 , indicating barite solubility is not $\mathrm{pH}$ dependent. Sulfur concentrations were below the detection limits of ICP-OES and not provided. No assessment of biomass (e.g., cell counts) was made during the course of these reactions, but visual inspection of the incubations showed no increase in turbidity or change of color in brine samples containing inoculant versus controls. In fact, visual inspection shows the turbidity of the solutions containing bacteria decreases slightly (relative to that of the brine control) by Day 34 in Fig. S2 in supplemental information. Cells were visually observed using microscopy, although biomass was not quantified.

Figure 2 shows the results of batch Experiment 2 in which barite crystals were placed in dialysis membrane bags to prevent direct contact with bacteria. The pore size of the dialysis membrane $(\sim 4 \mathrm{~nm})$ is too small for the bacteria in our cultures (size $\sim 1-2 \mu \mathrm{m}$, see Figure 3 ) to pass through and make direct contact with the barite surface. In all experiments, sterile media was added to the dialysis bag containing barite (as described in the methods) to maintain ionic conductivity with the solution outside of the bag. This internal solution was combined with the bulk solution in the bottles prior to $\mathrm{Ba}$ analysis. Figure 2 shows that $\mathrm{Ba}$ is released in the presence of PW cultures at a higher rate than brine controls, particularly for those inoculated with the CU823 consortia as shown at $\mathrm{T}=30$ days in Figure 2.

As indicated previously, prior to inoculation the artificial brine solution was slightly turbid (see Fig. S2 in supplemental information) due to a suspension of solids that have no definitive crystal structure from XRD (not shown). The turbidity of the brine generally decreases with time in all inoculated experiments. At each sampling event, the liquids were filtered prior to elemental analyses in order to account for Ba-containing precipitates that may form during the experiment (e.g., $\mathrm{BaCO}_{3}, \mathrm{BaS}$ ), Ba-sorbed to solids and/or $\mathrm{Ba}$ that is incorporated into biomass. Table S1 shows $\mathrm{Ba}$ analysis of the filtered solids taken from the brine control and inoculated 
Ouyang et al.

brine samples; the amount of $\mathrm{Ba}$ in the solids generally accounts for $<1 \%$ of the total $\mathrm{Ba}$ in solution after 30 days (Table S1). For samples reacted in fresh water control and fresh water $+D$. vulgaris, the amount of $\mathrm{Ba}$ in the solids is shown to reach upwards of $80 \%$ of the total $\mathrm{Ba}$ in solution (Table $\mathrm{S} 1$ ), however the total amount of $\mathrm{Ba}$ in the dissolved and solid phases is insignificant compared to Ba totals in brine experiments.

\subsection{Barite surface morphologies}

In order to elucidate possible dissolution mechanisms, the barite (001) surface was examined using SEM at each sampling interval. Previous studies have shown that dissolution features, or "etch pits", initiate at defect sites on the (001) and grow deeper and laterally over time when solution conditions are undersaturated with respect to barite (Becker et al., 2005; Kowacz and Putnis, 2008; Risthaus et al., 2001). No obvious etch pits were observed on barite reacted in freshwater (with or without SRB) in accordance with relatively low dissolved Ba concentrations in solution (Fig. 1). However, barite directly exposed to the brine control solution developed elongated etch pits with curved edges more or less parallel to [010] within 10 days as shown in (Fig. 4 A); this etch pit type (herein designated as Type A and shown schematically in Fig. 4) is the predominant etch pit morphology on the flat terraces of the (001) face and occur relatively homogeneously on the surface. Remarkably, the distribution of etch pit morphologies that develop in the presence of the three different bacteria enrichment cultures are qualitatively different from the control. Relatively-deep, rectangular etch-pits with dimensions $\leq 10 \mu \mathrm{m}$ (long edge) and a morphology shown in Fig. 4B (herein designated as Type B and shown schematically in Fig. 4) occur in patches on the surface and are only present on barite from inoculated experiments. Type B pits are oriented parallel to [010], similar to Type A. It should be noted that both Type A and B etch pits are present on surfaces exposed to bacteria. Type B 
Ouyang et al.

etch pits occur in greater abundance on samples analyzed during the first 30 days; eventually becoming less numerous on samples taken on days 80 and 135 .

Figures 4C, 4D and 4E show barite (001) surfaces that were contained within dialysis membranes for the brine control and the CU823 consortia after 10 and 30 days, respectively. The crystals display etch pit morphologies consistent with those found for barite directly immersed in the solutions; specifically, Type B etch pits are only present on surfaces from experiments containing microbes whereas Type A etch pits are present in both conditions (barite in the control and bacteria treatments). Thus, the physical isolation of the barite from microbes does not appear to influence the morphological development of etch pits. Similar features were observed for barite exposed to bacteria from MA284 and ST460 as shown in Fig. S2 in supplemental information. Figure 5A shows an AFM image of a barite (001) surface that was isolated from the brine and CU823 consortia by dialysis membrane for 10 days. Etch pit dimensions were determined from AFM to be $\sim 3 \mu \mathrm{m}$ long, $\sim 1.5 \mu \mathrm{m}$ wide, and $1 \mu \mathrm{m}$ deep.

We analyzed the aspect ratios of 66 etch pits, i.e., ratio of long dimension (L) to the short dimension (W), for Type B etch pits from a 10 day Experiment 2 bottle containing the CU823 culture. Aspect ratios were determined for etch pits randomly sampled from a population of etch pits exhibiting a wide range of sizes, defined here by area $\left(\mathrm{L} \times \mathrm{W}=0.8-9.7 \mu \mathrm{m}^{2}\right)$. The average ratio, L:W, was $2.0: 1( \pm 0.1)$ and this value is constant over the entire range of etch pit surface areas. A similar dimensional analysis for etch pits formed on the surface during DTPA dissolution (Fig. 5B) shows a similar L:W ratio of $2.1: 1( \pm 0.2)$ for etch pit areas spanning three over orders of magnitude. The consistency of the aspect ratio for etch pits of vastly different areas suggests that etch pit dimensions are likely controlled by the rates of the dissolution reactions occurring at each step edge and not by an end to end coalescence of smaller pits. 
Ouyang et al.

Specifically, the results suggest that the dissolution rate is twice as fast in the long direction [010] than in the short direction [100]).

\section{Discussion}

This study provides a fundamentally new perspective on the mechanism of barite dissolution by considering the role of microorganisms in anoxic and hypersaline environments. First, we established a baseline for the dissolution rate of the barite (001) surface under abiotic conditions. The increased rate of barite dissolution in brine control relative to FW control (indicated in Figs. 1 and 2) is consistent with results of previous studies showing that dissolution rate increases with increasing concentration of ions in solution (Putnis et al., 2008; Kowacz et al., 2008; Kowacz et al., 2009). An increase in barite dissolution rate with increasing concentration of background ions other than $\mathrm{Ba}^{2+}$ and $\mathrm{SO}_{4}{ }^{2-}$ is commonly attributed to the ionic strength effect (Buhmann et al. 1987). The ionic strength effect results from the strong, long-range electric fields produced by background ions in solution that reduce the activity of $\mathrm{Ba}^{2+}$ and $\mathrm{SO}_{4}{ }^{2-}$ ions (due to charge screening effect) and increase barite solubility relative to its solubility in pure water. Furthermore, previous studies indicate that the rate of barite dissolution is affected by the ability of background ions to modify solvent structure dynamics (Kowacz et al., 2008). Specifically, the presence of dissociated ionic species such as non-associated background ions (Kowacz et al., 2008) and deprotonated organic molecules containing carboxylate functional groups (Kowacz et al., 2009) stabilize the water of hydration surrounding $\mathrm{Ba}^{2+}$ and $\mathrm{SO}_{4}{ }^{2-}$ (i.e., increase the residence time of $\mathrm{H}_{2} \mathrm{O}$ in the hydration shell), thus increasing the dissolution rates of $\mathrm{Ba}^{2+}$ and $\mathrm{SO}_{4}{ }^{2-}$ ions relative to their rates in pure water.

The presence of microorganisms in the brine is shown to increase the rate of barite dissolution relative to the brine control. The fact that the rates for Experiment 2 show the same 
Ouyang et al.

trend as those in the Experiment 1 suggests that the mechanism responsible for the increased rate does not depend on the microbes making direct physical contact with barite. Although previous studies indicate that some halophilic bacteria are capable of reducing sulfate to sulfide (Daly et al., 2016; Liang et al., 2016), we did not observe any sulfide formation in our experiments. Therefore, a possible explanation for the similar trend in rates between Exps. 1 and 2 is that bacteria in each of these consortia are secreting an organic compound or a mixture of organic compounds (i.e., metabolites) during their metabolic process that is small enough to pass through the dialysis membrane and promote dissolution. In this scenario, the mechanism promoting dissolution may be: 1) organic ligands directly complex $\mathrm{Ba}^{2+}$ exposed on the surface and facilitate the detachment of $\mathrm{Ba}^{2+}$ ions into solution, and/or 2) ligands with charged functional groups stabilize the waters of hydration surrounding $\mathrm{Ba}^{2+}$ and $\mathrm{SO}_{4}{ }^{2-}$ at the surface (via the previously described mechanism). Organic ligand-assisted dissolution is well known for minerals such as iron oxyhydroxides, for example, where ligands strongly bind with iron on the mineral surface and increase dissolution rates by facilitating iron detachment from the surface (Kraemer et al., 1999; Reichard et al., 2007; Stumm and Sulzberger, 1992; Wiederhold, 2006). Metabolite promoted dissolution has also been shown for apatite surfaces due to complexation of $\mathrm{Ca}^{2+}$ by organic acids (Welch et al. 2002). However, there are no previous studies linking microbial metabolites with barite dissolution. A comprehensive metabolomics analysis was out of the scope of this initial study, however a quantitative evaluation of dissolution etch pit morphologies provides additional evidence for organic-ligand promoted dissolution.

Etch pit morphologies provide insight into molecular-scale interactions that control dissolution of specific crystallographic faces of minerals. For example, the type A etch pit morphology observed on the barite (001) surface exposed to the brine control (Fig. 4A and 4C) is 
Ouyang et al.

consistent with morphologies reported for dissolution of barite (001) under high ionic strength conditions (e.g., $1 \mathrm{M} \mathrm{NaCl}$ ). This morphology type is explained by first considering dissolution in pure water where monolayer-deep triangular etch pits bound by step edges parallel to [010] and [120] and [12̄0] are observed (Becker et al., 2005; Kowacz and Putnis, 2008; Pina et al., 1998b; Risthaus et al., 2001). Increasing the ionic strength of the dissolving solution stabilizes the monolayer step edges running parallel to the [010] relative to step edges parallel to the [120] and $[1 \overline{2} 0]$ as described by previous studies (Becker et al., 2005; Kowacz and Putnis, 2008; Risthaus et al., 2001). The result is that the rate of dissolution of the $\{120\}$ step edges increases relative to dissolution of the [010] and promotes the curve-shaped etch pits elongated in the [010] direction typified by the Type A morphology.

Remarkably, the distribution of morphologies of deep etch pits changes when microbial cultures are present in solution. Specifically, the Type B etch pits only appear in the presence of bacteria (e.g., CU823 in Figs. 4B and 4D) in both Type 1 and Type 2 experiments. The morphology of these etch pits (Type B) are visibly different than those of the brine controls (Figs. 4A and 4C) and are characterized by a long axis (lengths $\leq 10 \mu \mathrm{m}$ ) that is bound by step edges that are parallel to the [010] direction and terminations at both ends by either a straight edge or an obtuse angle with values between approximately $97^{\circ}$ and $116^{\circ}$. The Type B morphologies also appear when crystals are exposed to bacteria from MA284 and ST460, but are not as distinct as in CU823. The reason for this difference is not clear. It may be due to variation in the composition of the microbial populations in the cultures or due to variability in cell abundance across the cultures. Akob et al. (2015) reported variability in cultures MA284 and ST460 compared with CU823, although all three cultures were dominated by Halanaerobium species. In addition, we observed in other experiments that all of the enrichment 
Ouyang et al.

cultures grow to the same total cell abundance $\left(\sim 10^{6}\right.$ cells per $\left.\mathrm{mL}\right)$ after 6 months of growth, suggesting that total abundance is not the sole source of variability in dissolution between cultures. However, variability in growth curves is not known and lag phases in growth may vary across the cultures.

The Type B morphology that forms in the presence of bacteria is morphologically identical to the well-described morphology that develops on barite (001) surfaces exposed to organic chelating molecules such as ethylenediaminetetraacetic acid (EDTA), diethylenetriaminepentaacetic acid (DTPA), and trans-1,2-cyclohexylenediaminetetraacetic acid (CDTA) (Kowacz et al., 2009; Putnis et al., 1995a; Putnis et al., 2008; Wang et al., 1999, 2000). These widely used commercial and industrial chelators contain multiple negatively charged carboxylate functional groups (-COO) ${ }^{-}$and have structures similar to natural chelators produced by bacteria in soil pore water and surface and ground water. In order to verify the correlation, we also treated our barite crystals with $0.005 \mathrm{M}$ DTPA in $0.72 \mathrm{M} \mathrm{NaCl}(\mathrm{pH} 10)$ and used AFM to image etch pits that form on the surface. Figure 5B shows the (001) surface after 35 minutes of dissolution. The morphology of the deep etch pits that form in the presence of DTPA are morphologically identical to the pits that form in the presence of bacteria in our study. Similar aspect ratios for etch pits formed under DTPA-promoted dissolution and bacteria-promoted dissolution suggest a similar mechanism may be controlling morphology development in these different experiments.

For DTPA-promoted dissolution, the formation of this specific morphology has been attributed to the fact that the larger organic molecules like DTPA (relative to $\mathrm{H}_{2} \mathrm{O}$ ) can only complex $\mathrm{Ba}^{2+}$ cations that are at the same structural level (i.e., the topmost cations exposed on the (001) surface). Thus, DTPA is restricted, based on its molecular length $(\sim 11 \AA)$, to 
Ouyang et al.

coordinating $\mathrm{Ba}^{2+}$ cations along step edges parallel to the [010] and [110] directions as shown in Putnis et al. (1995). Since dissolution proceeds by the removal of half unit cell layers $(3.5 \AA$ deep), trapezohedral-shaped pits appear in two different orientations related by a $2_{1}$ screw axis parallel to the c crystallographic axis. Additionally, studies show that specific conformations of DTPA molecules can yield etch pit morphologies terminated by step edges along the [ $\overline{1} 10]$ and [120] directions which are similar to some of the Type B morphologies that develop in our experiments shown in Fig. 4 (Wang et al., 1999, 2000).

The observed etch pit morphologies in our experiments indicate that the bacterial cultures, dominated by Halanaerobium species, are likely producing sufficient quantities of an organic molecule(s) that is small enough to pass through the dialysis membrane and promote barite dissolution in a similar fashion to strong industrial chelators such as EDTA, DTPA, and CDTA. The known mechanisms to form a Type B morphology suggest that the molecule has similar molecular dimensions and functional groups that are deprotonated at a $\mathrm{pH}$ of $\sim 6.5$. It should be noted that other factors, including temperature and ionic strength, have been shown to affect etch pit morphology development (Kowacz et al., 2008). Thus, identical morphologies is not definitive proof of an analogous mechanism. Furthermore, it is highly unlikely that a chelator molecule would be produced for the purpose of complexing $\mathrm{Ba}$ since $\mathrm{Ba}$ is not an element essential to cellular metabolic processes. However, bacteria are known to produce chelating agents to aid in the uptake of iron (e.g., siderophores) and other essential elements under conditions when the availability of these elements is limited. We suggest the possibility that a chelator compound being produced in our cultures may also promote barite dissolution, though further study is required to isolate and identify this compound. 
Ouyang et al.

In summary, our study shows that the presence of Halanaerobium cultured from Marcellus Shale PW promotes the dissolution of barite in anoxic solutions containing extremely high concentrations of $\mathrm{Na}^{+}$and $\mathrm{Cl}^{-}$ions. Specifically, bacteria from well CU823 are shown to increase the solubility of barite 4-5 $\times$ that of brine controls that do not contain bacteria during an 80-day incubation period. We suggest that bacteria are producing organic chelating molecules during their metabolic process that are either: 1) directly complexing with the surface and facilitating the detachment of $\mathrm{Ba}^{2+}$ ions into solution, or 2) modifying the hydration of $\mathrm{Ba}^{2+}$ at the surface. Specific etch pit morphologies that only appear in the presence of bacteria suggest the former rather than the latter, but more study is required to hone in on the identity of the organic molecules implicated in this study and possible dissolution mechanisms.

The results of this study highlight the importance of considering microbially-mediated dissolution of barite and associated radiobarite (as well as other formation and scale minerals) in the leaching of barium and radium in PW generated from oil and gas extraction. From an environmental and health standpoint, waste brines and solids from hydrocarbon extraction must be stored and then disposed of properly. Waste brine is typically stored in centralized storage impoundments or tanks prior to reuse as injection fluid, but eventually it is disposed of in deep saline injection wells, discharged to surface water, or treated at dedicated commercial waste treatment plants. The solids (or impoundment sludge) are often enriched in radium. The treatment of the waste brine often involves chemical precipitation of the dissolved ions and production of solids. During this process, effluent is discharged to surface water while precipitated solids and sludge containing barite, radiobarite and other salts are disposed of in a landfill. In some states, waste may also be spread over fields or on roadways (for deicing). It is unclear how much radium could be released as a result of these disposal practices and the 
Ouyang et al.

insolubility and slow dissolution kinetics of barite/radiobarite is often cited to support such practices. However, this study shows that microbial metabolites produced in these environments may promote dissolution and should be considered when assessing these disposal scenarios. 
Ouyang et al.

\section{Acknowledgments}

The authors would like to thank Joshua Landis for his analytical support in the study and George

O’Toole, Mukul Sharma, and Ed Landa for their helpful advice. This study was supported by Dartmouth College and the USGS Toxic Substances Hydrology Program, USGS Hydrologic Research and Development Program, and USGS Energy Resources Program. Appreciation is extended to Jean Micheal Chanchu for assistance culturing the PW enrichment cultures. Any use of trade, product, or firm names is for descriptive purposes only and does not imply endorsement by the U.S. Government. The authors declare no competing financial interest. 
Ouyang et al.

\section{Figure captions}

Figure 1. Barium concentrations in batch dissolution experiments (Experiment 1) at time $=1,10$, 30, 80 and 135 days. A culture from well CU823 shows elevated rates of dissolution over other inoculated experiments, brine controls, and both freshwater experiments. FW= freshwater media, $\mathrm{DV}=D$. vulgaris. *Missing data indicates samples that broke during transfer and were unrecoverable.

Figure 2. Barium concentrations in batch dissolution experiments (Experiment 2) at time $=1,10$, and 30 days. The difference between results shown here and those in Fig. 1 is that the barite crystals (here) were isolated from bacteria by a dialysis membrane. The culture from CU823 shows elevated rates of dissolution over other all other experiments. FW: freshwater media, $\mathrm{DV}=$ D. vulgaris.

Figure 3. SEM image of bacteria on the barite (001) surface from culture CU823 (time: 80 days).

Figure 4. SEM images of etch pits that develop on the barite (001) surface in (A, B) Experiment 1 and (C-E) Experiment 2 (dialysis membrane). (A) Elongated pits (resembling striations on surface, indicated by arrows) formed after exposure to brine control for 10 days (inset shows magnified Type A pits), black carbon-rich particles are also shown on surface. (B) Etch pits formed after exposure culture CU823 in brine after 10 days are relatively deeper, have a different morphology compared to 4A and have a consistent aspect ratio $\mathrm{L}: \mathrm{W}$ of $\sim 2$. (C) Elongated pits formed after exposure of a barite crystal within the dialysis membrane to brine control for 10 days similar to those in 4A. (D) Deep etch pits formed after exposure of a barite crystal within the dialysis membrane to the CU823 culture after 10 days show similar morphologies to those in 4B; (E) same as 4D except surface imaged after 30 days and deep etch pits are relatively larger in area.

Figure 5. AFM image of Type B etch pits formed on barite (001) surface: A) after 10 days in Experiment 2 with the CU823 culture. The depth of a representative etch pit denoted by the blue arrow is $\sim 1 \mu \mathrm{m}$ as shown in the cross section profile; and B) after dissolution in $0.005 \mathrm{M} \mathrm{DTPA}$ and $0.72 \mathrm{M} \mathrm{NaCl}(\mathrm{pH}=10)$ for 35 mins. Height and deflection images indicated in figure. 
Ouyang et al.

Tables

Table I. Experimental design for barite dissolution batch experiments.

\begin{tabular}{|c|c|c|c|c|}
\hline Experiment & Culture & Solution & Barite Form & $\begin{array}{l}\text { Sampling time } \\
\text { points (days) }\end{array}$ \\
\hline \multirow{6}{*}{$\begin{array}{l}\text { 1- Dissolution } \\
\text { with direct } \\
\text { contact }\end{array}$} & CU823 & \multirow[t]{4}{*}{ Brine } & \multirow[t]{6}{*}{ Crystal } & \multirow[t]{6}{*}{$10,30,80,135$} \\
\hline & MA284 & & & \\
\hline & ST460 & & & \\
\hline & None, abiotic control & & & \\
\hline & D. vulgaris & \multirow[t]{2}{*}{ Freshwater } & & \\
\hline & None, abiotic control & & & \\
\hline \multirow{6}{*}{$\begin{array}{l}\text { 2- Dissolution } \\
\text { without direct } \\
\text { contact }\end{array}$} & CU823 & \multirow[t]{4}{*}{ Brine } & \multirow{6}{*}{$\begin{array}{l}\text { Crystal in } \\
\text { dialysis } \\
\text { membrane }\end{array}$} & \multirow[t]{6}{*}{10,30} \\
\hline & MA284 & & & \\
\hline & ST460 & & & \\
\hline & None, abiotic control & & & \\
\hline & D. vulgaris & \multirow[t]{2}{*}{ Freshwater } & & \\
\hline & None, abiotic control & & & \\
\hline
\end{tabular}




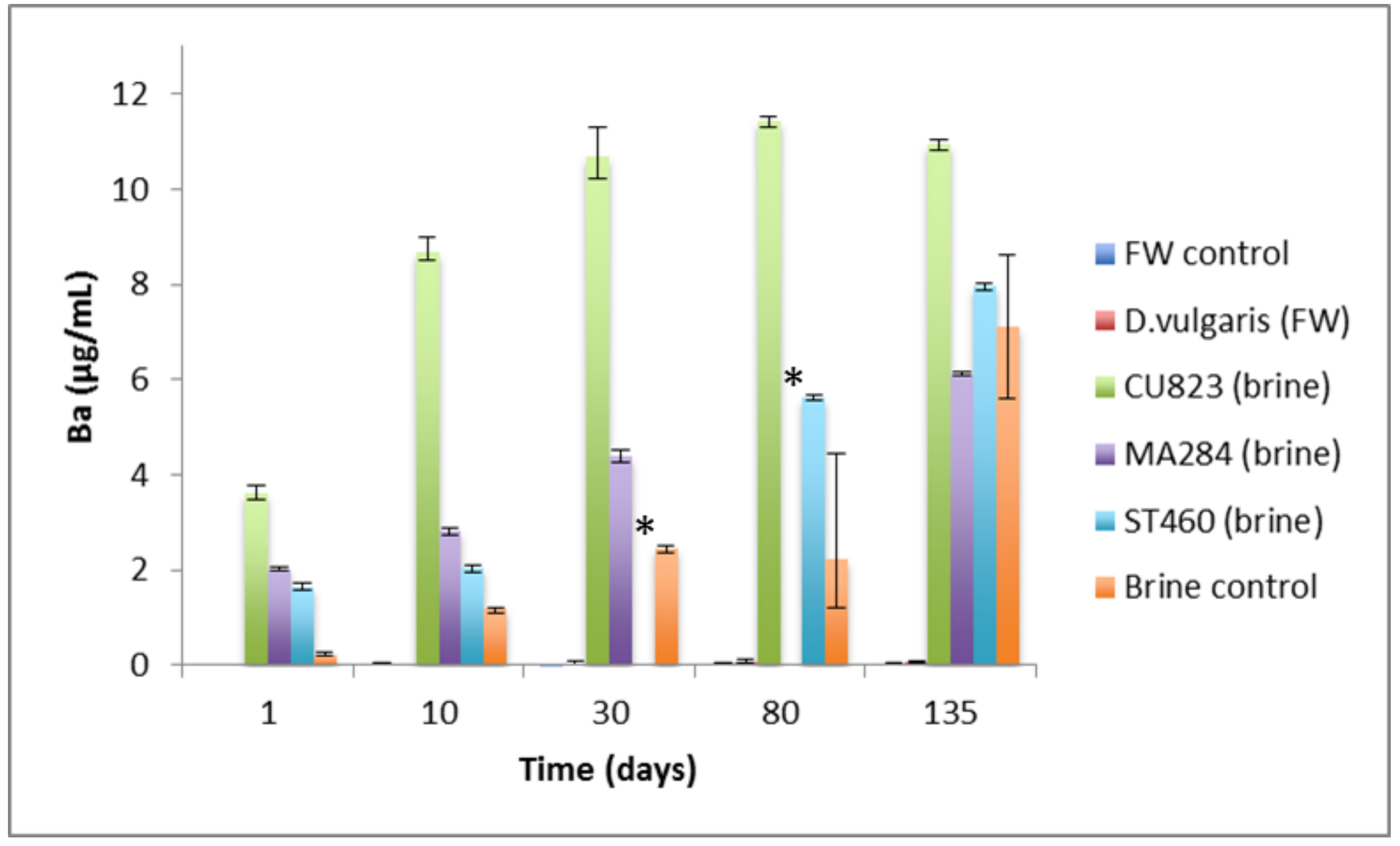

Figure 1. 


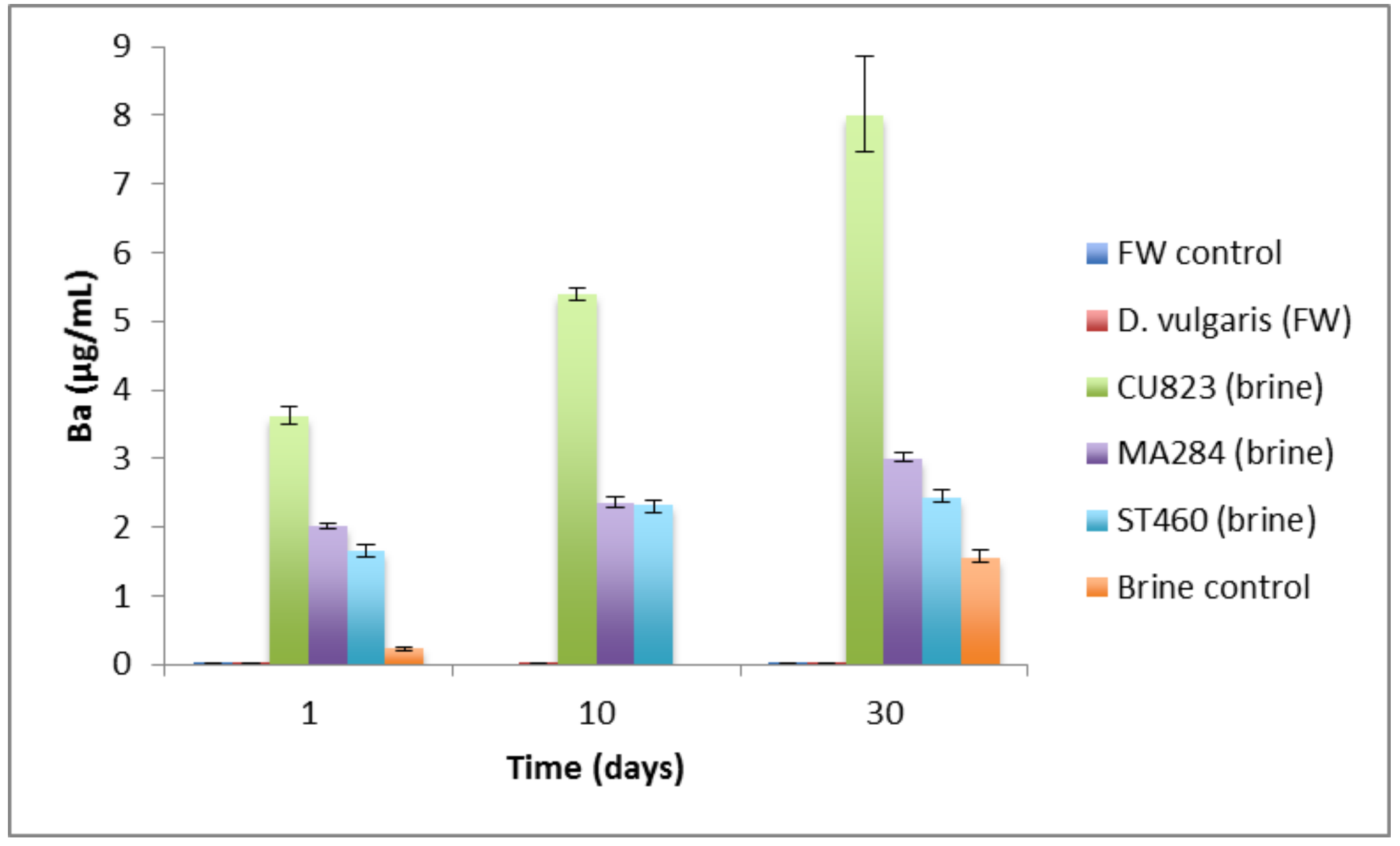

Figure 2. 


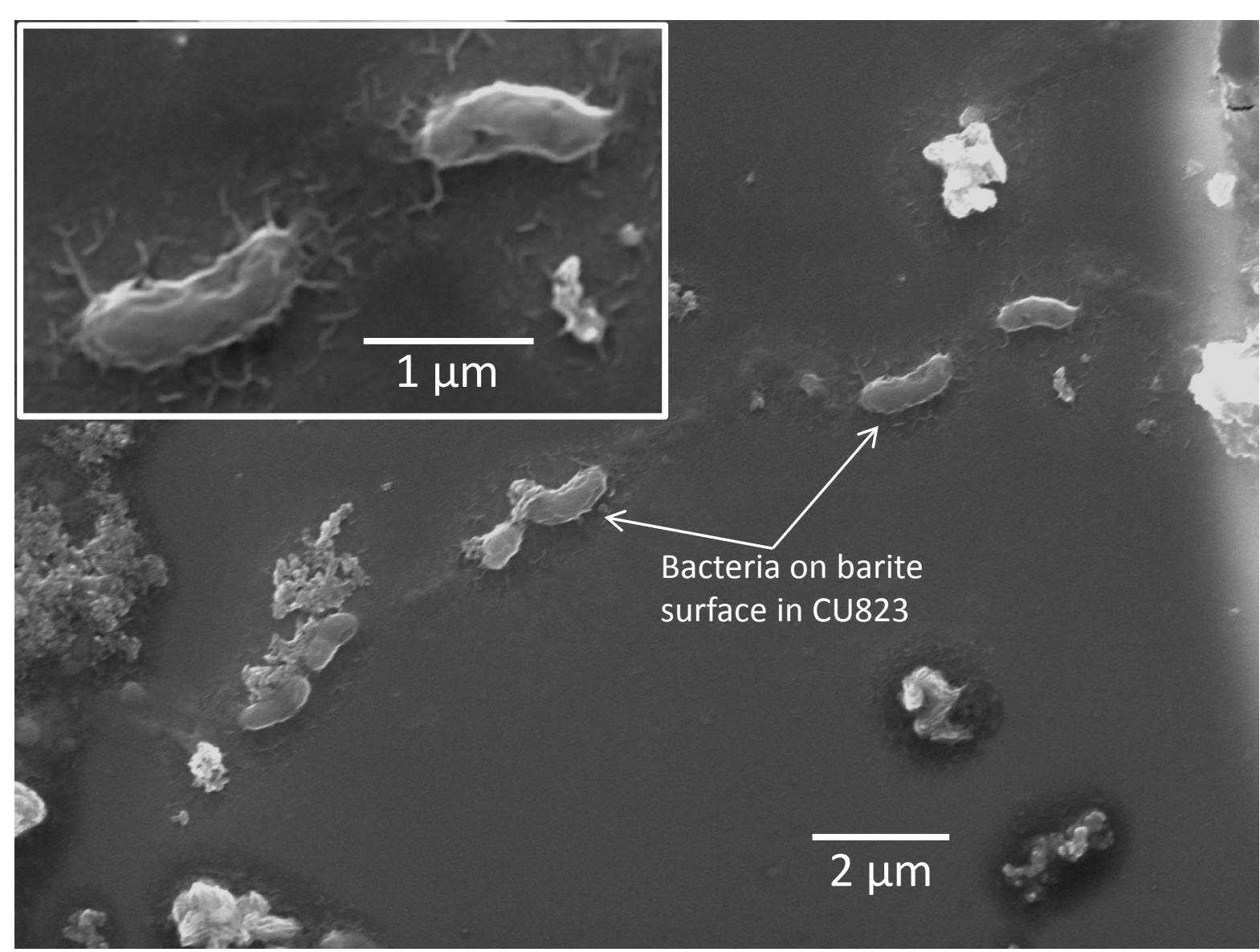

Figure 3. 

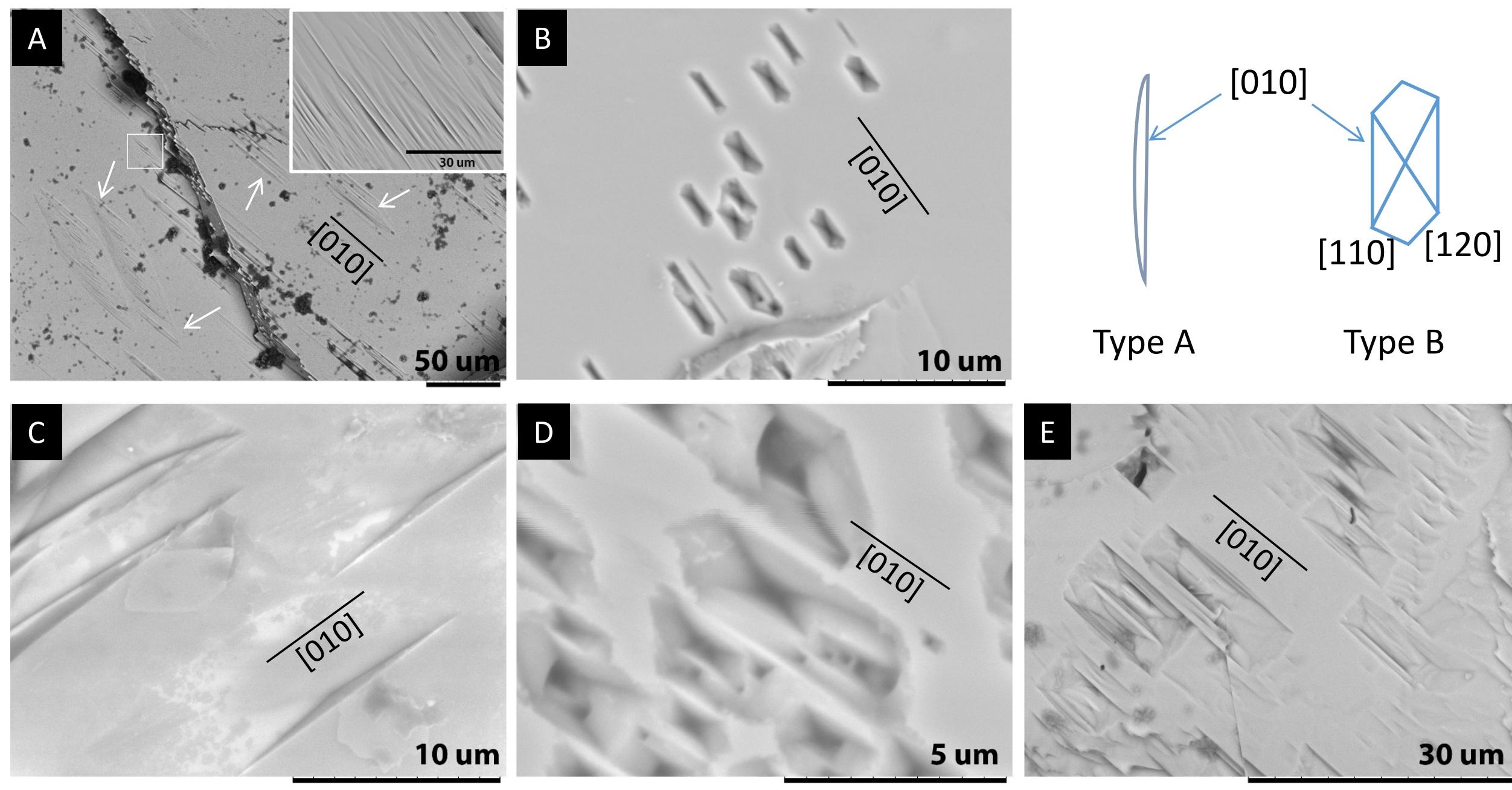

D

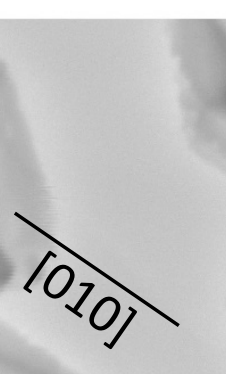

Type A

Type B

Figure 4. 

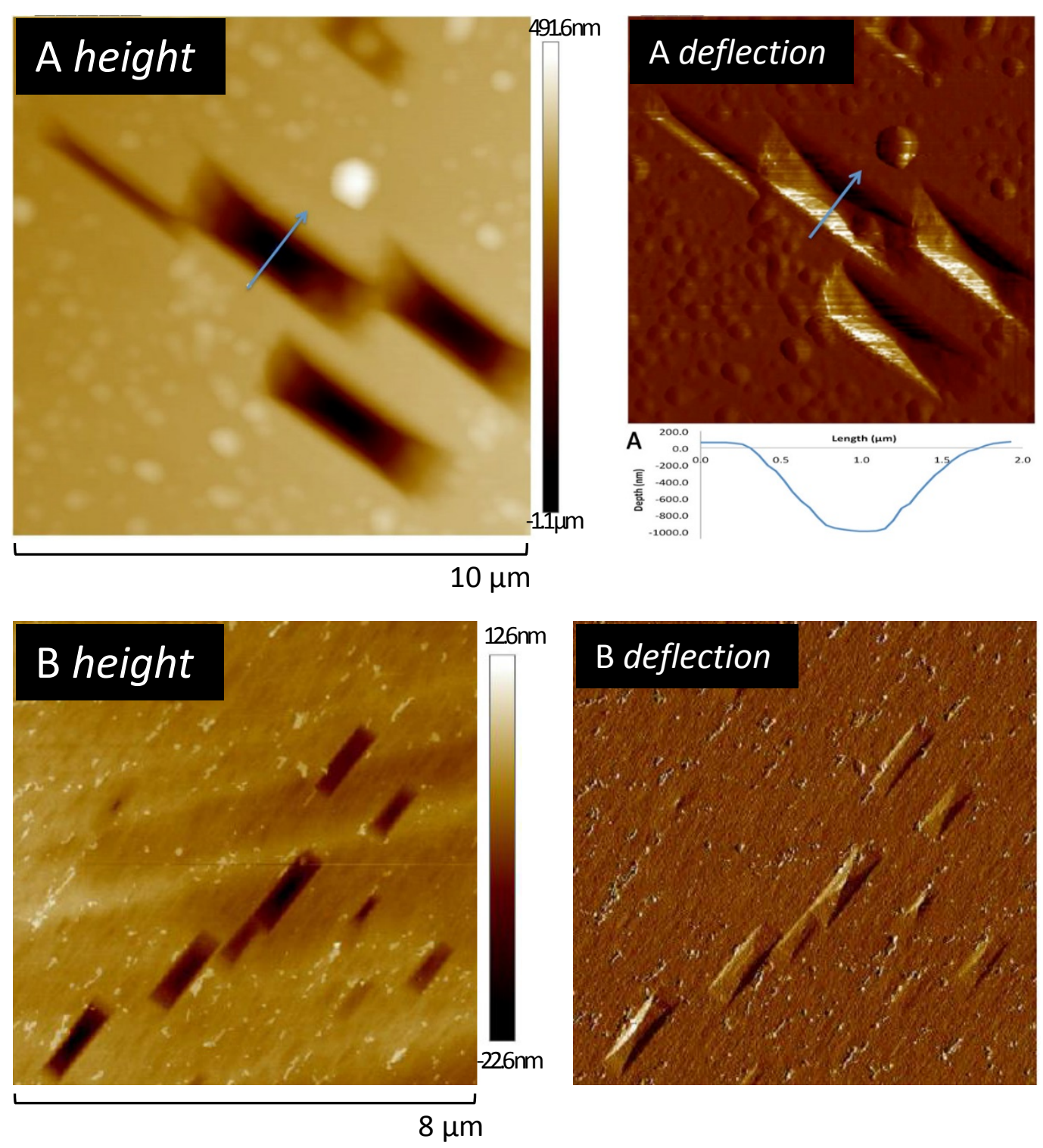

Figure 5. 